\title{
O jogo dramático com mulheres de uma comunidade: revelando potências de desenvolvimento humano e social
}

\author{
A dramatic game with women from a community: revealing the potential of \\ human and social development
}

\section{El juego dramático con las mujeres de una comunidad: revelar competencias de desarrollo humano y social}

\author{
Ana Carolina Faria Maniglia Comparini \\ Uni-FACEF Centro Universitário de Franca - e-mail: aninhafaria28@gmail.com \\ Daniela de Figueiredo Ribeiro
}

Uni-FACEF Centro Universitário de Franca - e-mail: ribares@netsite.com.br

Antonio dos Santos Andrade

Faculdade de Filosofia, Ciências e Letras de Ribeirão Preto da Universidade de São Paulo (FFCLRP/USP) - e-mail: antandras@fffclrp.usp.br

\section{Angélica Teixeira Gomes}

Instituição: Escola de Enfermagem de Ribeirão Preto da Universidade de São Paulo (EERP/USP). - email: angeltexgomes@gmail.com

\section{Resumo}

A presente pesquisa buscou investigar as percepções de mulheres que vivenciaram uma intervenção grupal psicodramática sobre os efeitos e as transformações ocorridas durante e depois dessa experiência. O processo grupal foi constituído de dez encontros, com duração de 120 minutos cada e contou com a participação de 12 mulheres de uma comunidade de baixa renda, na faixa etária de 20 a 68 anos, que não exerciam atividades profissionais fora de casa, cinco delas eram mães e sete, avós. O jogo dramático envolveu e capturou a entrega das participantes ao fluxo de espontaneidade proposto, expresso na relação com elas mesmas, na relação com as demais participantes, com seus organismos, propiciando-lhes saúde e bemestar, e também na inserção em seus átomos sociais, produzindo desenvolvimento social.

Palavras-chave: Psicodrama. Psicoterapia de grupo. Desenvolvimento humano e social. Espontaneidade. Esquizoanálise.

\section{Abstract}

This research aimed to investigate the perceptions of women who experienced a 
psychodramatic group intervention, regarding the effects and changes that took place during and after. The group process consisted of 10 meetings, each lasting 120 minutes with the participation of 12 women from a low-income community, aged from 20 to 68, who do not work outside the home, and of whom five were mothers and seven grandmothers. The dramatic game involved and captured the way the participants gave themselves to the proposed flow of spontaneity, which was expressed in the relation to their personal being, in relation to the other participants, and with their bodies, allowing them health and well-being, and inclusion in their social atoms, producing social development.

Keywords: Psychodrama, Group psychotherapy. Human and social development. Spontaneity. Schizoanalysis.

\section{Resumen}

Esta investigación pretende investigar las percepciones de las mujeres que experimentaron una intervención psicodramática en grupo sobre los efectos y los cambios que tuvieron lugar durante y después de esta. El proceso consistió en diez sesiones, cada una con duración de 120 minutos, y tenía como el objetivo manejar la participación de 12 mujeres (cinco madres y siete abuelas) de una comunidad de bajos ingresos, entre 20 y 68 años, que no trabajaban fuera del hogar. El juego dramático involucró y capturó la entrega de las participantes al flujo de la espontaneidad propuesto, expresado en su relación con ellas mismas, en relación con las demás participantes y con sus cuerpos, permitiéndoles salud y bienestar e inclusión en sus átomos sociales, produciendo el desarrollo social.

Palabras-clave: Psicodrama. Psicoterapia de grupo. Desarrollo humano y social. Esquizoanálisis.

\section{INTRODUÇÃO}

Este artigo pretende contribuir para compreensão da importância do grupo de Psicodrama como uma estratégia de enfrentamento das questões em que a contemporaneidade força os indivíduos a superarem, bem como revelar o potencial construtivo desse dispositivo para o desenvolvimento pessoal e social de mulheres das classes populares responsáveis por suas famílias.

Em três estudos, Gomes e Silva Júnior (2007a, 2007b e 2008) buscaram compreender como os laços solidários que florescem entre amigos nas classes populares escapam aos imperativos neoliberais e resistem à situação de opressão. Esses estudos revelaram modos criativos e astuciosos de enfrentamento de condições espoliantes, contribuindo para reverter situações de penúria. Os laços de amizade podem constituir relações privilegiadas de experimentação de outras formas de relacionamento incompatíveis com os modelos individualistas e excludentes do capitalismo, intensificados na atualidade, e também podem compor relações de acolhimento, comprometimento com o outro e vivência da solidariedade. Isso pode indicar a psicoterapia de grupo como condição importante para a sobrevivência na contemporaneidade.

Nessa mesma perspectiva, Pereira e Pereira (2009) objetivaram estabelecer uma relação entre a forma de vida no mundo contemporâneo - caracterizado pela presença de refinadas tecnologias, pela deterioração das relações nas esferas coletiva e pública e pela 
excessiva individualização do ser humano, cujo resultado é o aparecimento das subjetividades privatizadas - e a cena das psicoterapias, entre elas o Psicodrama, suas possibilidades e seus limites na resolução dos sofrimentos psíquicos gerados nesse contexto. Os autores partem da ideia de conserva cultural de Moreno para destacar a possibilidade de a psicoterapia ser o espaço de resgate do caráter coletivo e político da subjetividade, amparando-se em uma associação entre a perspectiva de Moreno e os conceitos de imaginário instituinte (Castoriadis) e os fluxos desterritorializados do desejo (Deleuze).

Dessa forma, Freitas e Russo (2013) investigaram, por meio de entrevistas individuais, como a Psicoterapia Psicodramática Grupal tem sido utilizada em dez clínicas privadas de Minas Gerais, São Paulo e Goiás. Com base na análise de conteúdo das entrevistas, as profissionais encontram dificuldades na criação e na manutenção de grupos psicoterapêuticos, em razão dos obstáculos relacionados aos próprios clientes, às condições socioeconômicas e culturais e ao próprio psicoterapeuta. Os autores concluem que a psicoterapia de grupo em clínicas privadas precisa ser reconfigurada para que possa ser mais difundida, como já ocorre, por exemplo, com os grupos tematizados que tratam de um problema específico (grupo de diabéticos, pessoas com transtornos alimentares etc.).

A propósito dos grupos tematizados, Contreras (2013) trata de um dos distúrbios de alta prevalência nos tempos atuais - a depressão -, apresentando uma reflexão epistemológica, teórica e metodológica sobre a abordagem psicodramática como um modelo diagnóstico e psicoterapêutico e sua aplicação no tratamento de referido distúrbio. A autora parte de uma reflexão sobre diferentes pontos fundamentais do Psicodrama, o qual é analisado como um modelo com diversas ferramentas conceituais que penetram a prática clínica, como os conceitos de matriz, locus e status nascendi, além da teoria dos vínculos e de papel. No final, apresenta duas intervenções clínicas bem-sucedidas, realizadas no Centro de Estudos de Psicodrama do Chile, uma por meio do Psicodrama individual e a outra, Psicodrama em grupo.

Em outra intervenção, Jácomo (2014) realizou um grupo psicoterapêutico com pacientes portadores de câncer e seus cuidadores, destacando o Psicodrama nesses atendimentos. Após considerar as inter-relações entre o câncer, a psico-oncologia, o Psicodrama e a compreensão de J. L. Moreno sobre grupos, buscou investigar os efeitos da aplicação do Psicodrama no que se refere à teoria metodológica de tratamento, e sua relevância consiste em apresentar essas contribuições. Para demonstrar a eficácia do grupo psicodramático, utilizou-se de um estudo de caso, envolvendo paciente e cuidador.

Trabalhando ainda com pacientes com câncer, Wechsler et al. (2014) apresenta intervenções clínicas e socioeducacionais com crianças, com base nos trabalhos de psicoterapia individual, grupal e de trabalhos institucionais. Entre esses trabalhos, intervenções socioeducacionais na Casa do Grupo de Apoio ao Adolescente e à Criança com Câncer (GRAACC) que visam atender à demanda nos próprios locais em que ela se encontra, com isso, nos termos das autoras, respondem ao que, em Análise Institucional é referido como um movimento instituinte. Nessas intervenções, os autores assumem como pressuposto que a Realidade Suplementar pode ser de grande valia no trabalho familiar com crianças pequenas ao permitir a ressignificação das relações em status nascendi e a diminuição do sintoma.

Considerando a questão dos distúrbios alimentares, Vieira, Torres e Moita (2013) descrevem um programa de intervenção psicodramática para mulheres obesas, focado nas emoções. O programa parte da evidência de que o comportamento de ingestão alimentar compulsiva pode estar associado a perturbações emocionais intensas. O Psicodrama foi utilizado com o objetivo de liberar a espontaneidade e a expressão emocional, que poderia diminuir essas perturbações. Resultados preliminares apontam a eficácia dessa estratégia psicoterápica.

Os trabalhos até aqui citados, de modo geral, ilustram o valor e a eficácia do 
Psicodrama em grupos tematizados com objetivo de tratar problemas específicos decorrentes de situações consideradas patológicas (depressão, câncer, obesidade). A seguir, serão apresentados exemplos de intervenções psicodramáticas grupais voltadas para violência intrafamiliar e grupos de mulheres, uma vez que a intervenção a ser considerada no presente artigo se situa nesse contexto.

Ramos (2013) apresenta um trabalho de psicoterapia psicodramática grupal com participantes que eram encaminhados pelo sistema judiciário por se envolverem em situações de violência intrafamiliar, mais especificamente violência contra a mulher. Tratavam-se de grupos abertos que foram desenvolvidos em 16 a 18 encontros, com duração de três horas, com média de 30 participantes. A autora mostra a eficácia do Sociodrama no alcance da meta, de esclarecer os aspectos componentes dos vínculos conjugais em toda a sua complexidade, levando os participantes a vivenciarem as condições nas quais eles haviam se relacionado até então.

Zendron e Seminotti (2011) desenvolveram uma oficina psicodramática realizada com um grupo de mulheres que focalizou sua temática em sua relação com o dinheiro. O grupo foi composto por cinco mulheres e foram realizados quatro encontros com duração de três horas cada. O Psicodrama foi considerado um dispositivo que produz a visualização e a configuração da rede relacional das mulheres participantes. Com esse dispositivo foi possível cartografar, no sentido da Esquizoanálise de Deleuze e Guattari (2011), as linhas molares ou duras e as moleculares ou moles, sendo as primeiras associadas às conservas culturais e as últimas, à espontaneidade e à criatividade. Os autores concluem que a oficina se constituiu em um excelente agenciamento ou dispositivo de prevenção e promoção da saúde da mulher.

Gazziero e Danielski (2013) apresentam os resultados de um grupo de mulheres que manifestavam queixas relativas ao relacionamento conjugal. Foram realizadas dez sessões de Sociodrama com sete mulheres entre 25 e 38 anos. Segundo as autoras, por meio do desenvolvimento de um campo relacional descontraído com troca de experiências, objetivouse o resgate do papel conjugal dessas mulheres, a fim de ressignificar e criar uma nova complementaridade com seus parceiros, o que foi comprovado no final do estudo.

Dessa forma, contribuindo para o desenvolvimento de grupos psicodramáticos tematizados com mulheres, o objetivo deste artigo é apresentar e discutir os resultados de uma investigação das percepções das participantes de uma intervenção grupal psicodramática, com jogos dramáticos, sobre os efeitos e as transformações ocorridas durante e depois desse processo. Acompanhando a proposta de Pereira e Pereira (2009) e principalmente as sugestões teóricas de Zendron e Seminotti (2011), na discussão dos resultados, pretende-se complementar as análises baseadas no referencial do Psicodrama com outras derivadas da Esquizoanálise, contribuindo assim para o diálogo entre dois paradigmas.

\section{METODOLOGIA}

A intervenção grupal foi realizada como parte de um estágio em contexto comunitário realizado por Ana Carolina Faria Maniglia Comparini, uma das autoras deste artigo, durante o sétimo semestre do curso de Psicologia - março a junho de 2012 -, sob a supervisão de Daniela de Figueiredo Ribeiro, outra autora deste artigo. Essa intervenção contou com mulheres de uma comunidade da periferia de uma cidade do interior paulista. Utilizando-se da abordagem Psicodramática e dos recursos do jogo dramático, buscou-se construir um caminho de cuidado humano para o indivíduo em seu processo de subjetivação, por meio de uma ação que tem como pressuposto e princípio ético a singularização da existência. A estratégia pautou-se na valorização do homem em suas relações. Na proposta de ação psicodramática, o jogo dramático visa promover o lúdico com objetivo de trabalhar os conflitos que surgem e 
tem como característica fundamental a resposta de um indivíduo ante uma situação nova e uma nova resposta a uma situação velha. Yozo (1996) afirma que o jogo dramático leva o indivíduo a liberar sua espontaneidade e sua criatividade e aponta essa estratégia como: “(...) um meio de desentorpecer o corpo e a mente dos condicionamentos da vida atual, não permitindo a massificação nas conservas culturais" (YOZO, 1996, p. 17).

O processo grupal foi constituído de dez encontros, com duração de 120 minutos cada e contou com a participação de 12 mulheres de uma comunidade, que vivem em condições de risco social relacionado à pobreza. As mulheres com idades entre 20 e 68 anos, frequentadoras de uma instituição comunitária, onde ocorreram as sessões grupais, não exerciam atividades profissionais fora de casa, sendo a mais nova delas grávida do primeiro filho, quatro mães e sete avós.

A investigação dos efeitos da participação no grupo de Psicodrama foi realizada por meio de entrevistas semiestruturadas individuais com oito participantes, cerca de oito meses após o término da intervenção grupal, obedecendo a dois critérios de seleção: presença acima de 50\% nas sessões e assinatura do Termos de Consentimento Livre e Esclarecido. O projeto foi aprovado pelo Comitê de Ética em Pesquisa.

Os dados coletados nas entrevistas e durante o processo grupal proporcionaram a elaboração das categorias temáticas de análise, visando compreender a abrangência e as particularidades de cada assunto. Na análise final, que serviu na elaboração da sessão seguinte, considerou-se os resultados obtidos durante o processo de intervenção grupal e os resultados das entrevistas.

\section{RESULTADOS E DISCUSSÃO}

\section{A vivência da arte e do lúdico}

Nas entrevistas, as mulheres avaliaram as vivências psicodramáticas (brincadeiras, danças, fantasias, encenações, cantos, jogos de compartilhar ideias, percepções e sentimentos), como uma experiência prazerosa e alegre, capaz de promover relações de amizade e encontros, e também uma possibilidade de envolvimento afetivo com o outro (conversar, desabafar, trocar afetos e experiências pessoais, confraternizar), demonstrando que a estratégia lúdica adotada parece ser uma forma de estabelecer um processo de comunicação satisfatório entre as pessoas, trabalhando suas tensões, seus prazeres, suas fantasias, suas ansiedades e suas frustrações, ao devolver a liberdade de ação criativa. Os relatos a seguir podem ser observados como exemplos dos momentos marcantes:

“(...) o dia mais especial foi aquele em que tive que dançar, e eu levantei e dancei (...) gostei de ter dançado, foi muito legal" (Bela); "Tinha dia em que a gente dançava, fazia aquelas micagens, nossa! Era a coisa mais gostosa do mundo pra mim (...). O dia mais marcante foi aquele dia em que a gente dançou com aquelas fantasias de circo, o que mais me deixou feliz foi aquela brincadeira lá, foi alegre demais (...)" (Joana).

A arte e o brincar mostraram-se eficazes, havendo indícios de que houve um resgate da espontaneidade, primordial para uma existência saudável. Observou-se que o Psicodrama foi capaz de apresentar novas dimensões dos problemas existenciais das mulheres participantes da intervenção grupal: para Moreno (2011), a arte é privilegiada como maneira do homem se manifestar e se expressar. A fala de uma das participantes pode ser um exemplo da percepção da arte como ponto central no qual a vivência foi embasada: "Eu gostei tanto daquele dia em que fizemos o painel, aquilo me marcou muito, sabe, me senti tão bem em passar um pouquinho do que a gente sente colando aquelas figuras, né" (Lia). Outra fala 
também denota a presença do sentir-se bem, do prazer ao expressar sentimentos, e isso pode estar relacionado a uma necessidade e até a um desejo: “(...) não via a hora de chegar quartafeira pra ir lá, se ver, cantar, rir, (...) lá consegui ter isso (...) rimos, brincava, cantava (...)" (Vânia).

Essa valorização do lúdico, do espontâneo e do criativo já fora destacada nos estudos com grupos de mulheres, apresentados na Introdução (ZENDRON e SEMINOTTI, 2011; RAMOS, 2013; GAZZIERO e DANIELSKI, 2013). Com a promoção da espontaneidade e a quebra do enrijecimento das conservas culturais, o Psicodrama sempre produz seu efeito liberador, o qual é sentido pelas participantes com a entrega ao lúdico, à brincadeira, à arte, nesse caso, à dança. Por meio da liberação de seus corpos pela dança, pelos jogos dramáticos, as participantes são libertadas de seus papéis sociais tão enrijecidos (conserva cultural) pelas dificuldades e pela barreira cotidianas em razão de carências enfrentadas por elas.

Segundo Zendron e Seminotti (2011), aproximando esses conceitos daqueles da Esquizoanálise de Deleuze e Guattari (2011), pode-se relacionar as conservas culturais com as linhas molares ou duras da Cartografia, outro nome que se dá a esse referencial, enquanto a espontaneidade consisti na liberação das linhas flexíveis ou moleculares. Assim, pode-se afirmar que as participantes foram capturadas, ou se deixaram capturar, por linhas flexíveis ou moleculares em seus processos de participação nos jogos dramáticos, o que as liberou das estratificações rígidas próprias das linhas molares ou duras.

\section{Vínculos e amizade}

Nos relatos sobre a criação de novos vínculos de amizade no grupo foi revelado o desenvolvimento de sentimentos de afeto. A fala de Lia na entrevista revela o sentimento de amor em relação às demais participantes durante a confraternização de encerramento: "Gostei também da confraternização de quando acabou, aí a gente sente o amor um pelo outro, marcou bastante" (Lia). A presença marcante de trocas de afetos e compartilhamento de experiências pessoais foram demonstradas nas falas: “(...) na hora de abraçar alguém, de conversar, de falar da vida da gente, isso foi importante pra mim" (Lita); "Todo mundo foi legal, (...) todo mundo tem alegria um com o outro (...)" (Bela).

Todas as entrevistadas relataram a manutenção do relacionamento com as integrantes do grupo mesmo depois de seu término, inclusive as que representaram novos vínculos criados, preservando os hábitos de cumprimentar com beijos e abraços. Elas afirmam que conversam sobre a vivência do grupo, se preocupam umas com as outras, avaliam que é uma alegria quando se encontram, sempre acham sobre o que conversar; compartilham problemas e dificuldades e se fazem companheiras na vida em comunidade:

Com as que participaram do grupo, a gente se encontra, cumprimenta: - "Oi, tudo bom!" Beija, abraça... Pergunta: - "A senhora tá boa?" (...) a gente tem aquela amizade assim (...) gostosa (...) quando encontra, a gente comenta sobre o grupo... foi muito bom, ajuda muito, às vezes a gente precisa um dos outros (...) eu gosto de servir quando posso (...) me sinto bem em servir. A vida não é fácil pra ninguém (...). De primeiro, principalmente eu que sou nova aqui no bairro, ninguém nem se cumprimentava, e hoje não, a gente conhece, gosta, preocupa com os outros, pergunta como é que vai (...). É uma alegria quando encontra. (Lia)

Assim como também revelado pelos estudos revistos na Introdução, como os de Zendron e Seminotti (2011); Contreras (2013); Ramos (2013); Gazziero e Danielski (2013), o outro efeito constante propiciado pelo Psicodrama consiste na manifestação da espontaneidade não apenas consigo mesmo, na forma de uma entrega pessoal ao lúdico, mas 
também na relação com o outro, na construção de novos vínculos, autênticos, espontâneos, flexíveis e duráveis. Trata-se da espontaneidade em sua expressão social, aquilo que Moreno denominou de tele. Para a Esquizoanálise, trata-se também de, no convívio social, se deixar conduzir por linhas moleculares ou flexíveis nos agenciamentos.

\section{Promoção da saúde e bem-estar}

Mediante os relatos de melhora da saúde e bem-estar, apresentados durante as entrevistas, podemos afirmar que o processo grupal produziu consideráveis transformações subjetivas em suas integrantes, com ruptura de padrões estereotipados, contribuindo na promoção da saúde e dos direitos humanos.

As entrevistadas relataram melhoras na saúde e/ou no bem-estar, como exemplificam as falas das participantes Lia e Carmo:

"Foi muito bom pra mim (...) eu era muito depressiva, ficava muito triste, e hoje não. Quando quero ficar triste, eu me lembro da alegria (...)" (Lia); “(...) uma mudança que tive foi ter sarado. Por causa da doença ficava fechada, deprimida e agora aquele sentimento de tristeza acabou e fiquei bem. (...) tive depressão e melhorei tanto lá, né, foi lá que fui sarar (...) bem dizer, foi lá que sarei da depressão. Então achei bom, muito bom aquilo lá pra mim, me desenvolveu muito (...) porque ficava aqui só fechada, fechada aqui passando mal, aí depois que comecei participar do grupo lá, foi uma saúde pra mim" (Carmo).

Os efeitos da espontaneidade em seus dois aspectos primários, sobre si e na relação com os outros, não poderiam deixar de se expressar também no corpo dessas mulheres, como organismo. Ao serem atravessadas pelos fluxos de espontaneidade e se entregarem a eles, seus organismos provavelmente também passavam a funcionar melhor.

Uma evidência disso são os estudos que escolhemos para esse debate, como o de Contreras (2013) que desenvolveu um grupo psicodramático com paciente portadores de depressão e chegou a resultados satisfatórios, ou o de Jácomo (2014) que demonstrou a eficácia do grupo psicodramático de pacientes com câncer, ao compartilhar vivências, pensamentos, sentimentos e percepções, bem como promover estratégias positivas (favorecer a espontaneidade-criatividade e a reorganização das conservas culturais), utilizadas no manejo da doença, incorporando-as ao seu cotidiano. Também o de Wechsler et al. (2014) que atenderam a crianças com câncer. Ou ainda o de Vieira, Torres e Moita (2013) que realizaram grupo com mulheres obesas.

Consistente com essa perspectiva, Ramalho (2011) propõe que o adoecimento do sujeito, no que diz respeito aos aspectos psicológicos, é resultado de um adoecimento da espontaneidade e da criatividade, que ocasionam o adoecimento do papel, por causa das imposições sociais de funções ou dos papéis indesejados. Assim, para a autora, agir espontaneamente com saúde é apoiar-se nessas conservas e transpor seus limites, apresentando uma resposta original. É resgatar a flexibilidade, a liberdade, o poder e a criatividade, sendo capaz de agir, liberando-se de sentimentos de resignação e impotência impostos pelas conservas. Como o caráter conjunto é que confere a adequação à realidade, a transformação indispensável para a manutenção do estado saudável deverá ser sempre uma cocriação.

\section{Mudanças nas relações interpessoais}

Nos resultados encontrados, foi evidenciado que, com base na vivência de um espaço (contexto grupal) seguro pelas participantes, o drama social surgia no contexto dramático 
como possibilidade de unificar os dois contextos em uma só dimensão: as situações vividas no grupo e na sociedade.

Sete participantes perceberam mudanças nessas relações como: passar a conviver com os familiares com mais frequência, conviver melhor com os filhos e os netos, ter mais paciência, compreender, respeitar, ouvir e falar quando necessário, estar junto com as crianças para ler histórias, dançar, brincar, desenhar. Houve também relatos sobre conversar mais com os pais, se soltar mais dentro de casa e conversar com os familiares principalmente sobre si mesma e seu passado. Foi exaltada a criação de um momento de reunião da família para fazer oração, a iniciativa de aproximação de um membro familiar que estava distante, mudança de estado de humor (nervosa para mais calma) com os filhos e os netos. Foram observadas também mudanças na forma de se relacionar, principalmente conversas com familiares, foram relatadas conversas que promoveram a proximidade com os filhos.

Vemos, portanto, que o drama privado se insere no coletivo, enquanto o drama coletivo se insere no individual, demonstrando sua interdependência. Contudo, vemos ainda mais que o fluxo de espontaneidade ao qual aquelas mulheres se entregaram e as afetou na relação com elas mesmas, com o outro ali presente e na relação com seu próprio organismo, se ampliou, ou seja, poderíamos dizer com Deleuze e Guattari (2011), se rizomatizou para as relações em seus átomos sociais. Esta é uma consequência destacada também por Romano (2011) em seu trabalho.

\section{CONCLUSÃO}

Os jogos dramáticos pelo estímulo à espontaneidade mostraram-se eficazes como instrumentos de ação, proporcionando a expressividade com a valorização da afetividade, com indícios de que houve a transposição dos limites das conservas culturais, criando uma resposta original, primordial para uma existência saudável. Promoveu ainda às participantes importantes contribuições nos processos de formação e desenvolvimento, principalmente no que diz respeito à conquista de novos aprendizados, mudanças pessoais (transformações subjetivas), na autoimagem e no posicionamento diante da vida (transformações no ser e no viver), bem como mudanças nas relações interpessoais (transformações intersubjetivas), produzindo como consequência a promoção da saúde e do bem-estar.

Por meio das mudanças nas relações interpessoais, as participantes passaram a ser agentes em seus círculos sociais, representados pela família e por outras pessoas da comunidade, o que situa a intervenção grupal como uma ação social e política comprometida com a coconstrução transformadora da realidade e implicada em um resgate da cidadania.

Por último, como considerado na Discussão, assume-se que o jogo dramático foi capaz de envolver e capturar a entrega das participantes ao fluxo de espontaneidade, o qual, por sua vez, libertou-as de suas linhas duras ou molares, nos dizeres de Deleuze e Guattari (2011) ou nas palavras de Moreno (2011), de suas conservas culturais, permitindo um processo conduzido por linhas flexíveis ou moleculares, aquele da ação espontânea (ZENDRON e SEMINOTTI, 2011). Esse fluxo espontâneo se expressou não apenas na relação com elas mesmas, mas também na relação com as demais participantes, estabelecendo vínculos autênticos e duradouros, e consequentemente na relação com seus organismos, propiciandolhes saúde e bem-estar, e na inserção em seus átomos sociais, produzindo um desenvolvimento social. Em síntese, o Psicodrama mostrou-se um dispositivo eficaz para produção de desenvolvimento humano, pessoal e social. 


\section{REFERÊNCIAS}

CONTRERAS, G. R. Psicoterapia psicodramática: una forma de diagnóstico y tratamiento para la depresión. Revista Brasileira de Psicodrama. São Paulo, v. 21, n. 2, 2013, p. 53-64. DELEUZE, G.; GUATTARI, F. Mil Platôs: Capitalismo e Esquizofrenia 2. 2a ed. São Paulo: Ed. 34, 2011.

FREITAS, A. P.; RUSSO, A. L. T. Psicoterapia Psicodramática grupal em clínica privada: terapeutas e seus desafios. Revista Brasileira de Psicodrama. São Paulo, v. 21, n. 1, 2013, p. 67-80.

FIGUEIREDO, M. A porta sociométrica da alegria: uma celebração à vida. Revista Brasileira de Psicodrama. São Paulo, v. 7 n. 2, 1999, p. 77- 94.

GAZZIERO, M. C.; DANIELSKI, W. C. Sociodrama e conjugalidade: um estudo com um grupo de mulheres. Revista Brasileira de Psicodrama. São Paulo, v. 21, n. 2, 2013, p. 133140.

GOMES, L. G. N.; SILVA JÚNIOR, N. S. Experimentação política da amizade: Alteridade e solidariedade nas classes populares. Psicologia: Teoria e Pesquisa. Brasília, v. 23, n. 2, abr.-jun. 2007a, p. 149-158.

. Sobre a amizade em tempos de solidão. Psicologia \& Sociedade [on-line]. V. 19, n. 2, mar. 2007b, p. 57-64.

Implicações políticas da semântica familialista nos discursos de amizade contemporâneos. Psicologia em Estudo. Maringá, v. 13, n. 2, abr.-jun. 2008, p. 267-275.

JÁCOMO, R. C. R. R. Psicoterapia de grupo psicodramática com pacientes oncológicos e seus cuidadores. Revista Brasileira de Psicodrama. São Paulo, v. 22, n. 2, 2014, p. 55-61.

MORENO. Psicodrama. 13. ed. São Paulo: Cultrix, 2011.

PEREIRA, A. H.; PEREIRA, O. P. A psicoterapia no mundo contemporâneo: um affaire coletivo e político. Revista Brasileira de Psicodrama. São Paulo, v. 17, n. 2, 2009, p. 33-48.

RAMALHO, C. M. R. Psicodrama e Dinâmica de Grupo. São Paulo: Iglu, 2011.

RAMOS, M. E. C. Homens e mulheres envolvidos em violência e atendidos em grupos socioterapêuticos: união, comunicação e relação. Revista Brasileira de Psicodrama. São Paulo, v. 21, n. 1, 2013, p. 39-54.

ROMANO, C. T. Tempo para se relacionar: átomo social e saúde física e mental. Revista Brasileira de Psicodrama. São Paulo, v. 19, n. 1, 2011, p. 123-134.

VIEIRA, F. M.; TORRES, S.; MOITA, G. Psicodrama e obesidade: desenvolvimento, implementação e avaliação de um programa de intervenção focado nas emoções. Revista Brasileira de Psicodrama. São Paulo, v. 21, n. 2, 2013, p. 141-149.

WECHSLER, M. P. F. et al. Psicodrama com crianças: das intervenções clínicas às psicossociais. Revista Brasileira de Psicodrama. São Paulo, v. 22, n. 2, 2014, p. 25-35.

YOZO, R. I. K. 100 jogos para grupos: Uma abordagem psicodramática para empresas, escolas e clínicas. 18. ed. São Paulo: Ágora, 1996.

ZENDRON, C. C.; SEMINOTTI, N. A. Papéis sociais femininos e as conservas culturais em relação ao dinheiro: cartografia de uma oficina temática de Psicodrama. Revista Brasileira de Psicodrama. São Paulo, v. 19, n. 1, 2011, p. 103-113.

Recebido: 04/02/2015

Aceito: 04/03/2016 
Ana Carolina Faria Maniglia Comparini. Psicóloga pelo Centro Universitário Municipal de Franca (Uni-FACEF), 2013. Cursando especialização em Psicodrama (nível I) pelo Celeiro - Espaço Sociodramático de Franca. Psicoterapeuta individual em clínica particular. Voluntária em instituição comunitária no município de Franca - SP (Psicóloga institucional e condução de grupos comunitários). Rua José Salomoni, 410, Bairro São José, CEP 14401298, Franca, SP. Tel.: (16) 3722-0065. E-mail: aninhafaria28@gmail.com

Daniela de Figueiredo Ribeiro. Psicóloga Faculdade de Filosofia, Ciências e Letras de Ribeirão Preto da Universidade de São Paulo (FFCLRP - USP). Doutorado pela FFCLRP USP. Psicodramatista (nível I, pelo Instituto de Psicodrama de Ribeirão Preto; nível II e nível III, pelo Celeiro - Espaço Sociodramático de Franca). Psicoterapeuta individual e de grupo no Celeiro - Espaço Sociodramático de Franca. Docente do Departamento de Psicologia e do PPGDR do Uni-FACEF - Centro Universitário Municipal de Franca. Rua Virgílio Pereira, 1625 Centro, CEP 14400-000, Franca, SP. Tel.: (16) 3702-5303. E-mail: ribares@netsite.com.br.

Antonio dos Santos Andrade. Mestre e Doutor em Psicologia pela Universidade de São Paulo (USP). Pós-Doutorado no Programa de Pós-Graduação em Educação Especial da Universidade Federal de São Carlos. Psicodramatista, Terapeuta de aluno e supervisor de Psicodrama pelo Instituto de Psicodrama de Ribeirão Preto. Docente do Departamento de Psicologia da Faculdade de Filosofia, Ciências e Letras de Ribeirão Preto da Universidade de São Paulo (FFCLRP - USP). Avenida Caramuru, 2450, ap. 76, Torre 3, Bairro Alto da Boa Vista. CEP 14025-710. Ribeirão Preto, SP. Tel.: (16) 3235-1847 e 3315-3803. E-mail: antandras@ffclrp.usp.br.

Angelica Teixeira Gomes. Psicóloga pela Universidade de Franca. Psicoterapeuta e Psicodramatista (nível I), pelo Celeiro Espaço Sociodramático (Franca, SP). Mestre em Psicologia pela Faculdade de Filosofia, Ciências e Letras de Ribeirão Preto da Universidade de São Paulo (FFCLRP - USP). Doutoranda em Ciências pela Escola de Enfermagem de Ribeirão Preto da Universidade de São Paulo (EERP - USP). Rua Virgílio Pereira, 1625 Centro, CEP 14400-000, Franca, SP. Tel.: (16)3702-5303. E-mail: angeltexgomes@gmail.com. 